\title{
Papers
}

Professor Richard Harper is professor of socio-digital systems and director of the Digital World Research Centre at the University of Surrey. Professor Harper has been at the forefront of research into the use of interdisciplinary techniques for specifying the requirements and role of new interactive technologies in organisational and domestic life. He has published over 100 articles and books.

Brian Shatwell manages future technology research for the Royal Mail to find new technologies that can be applied to the mail to provide new customer services and improve effectiveness. Before joining the Royal Mail in 1994, he was involved in advanced technology-based products for his entire career. This included developing disk drives, through global communication systems and on to electronics on Formula 1 racing cars.

Keywords: paper mail, affordances, home life, domestic settings, ethnography, interactive systems design

\section{The end of the letter}

Professor Richard Harper Digital World Research Centre School of Human Sciences University of Surrey Guildford

Surrey

GN5 7XH, UK

Tel: $44(0) 1483259446$

Fax: $44(0) 1483689550$

E-mail: r.harper@surrey.ac.uk

\section{Paper mail in the home of the 21 st century: An analysis of the future of paper mail and implications for the design of electronic alternatives}

\author{
Richard Harper and Brian Shatwell \\ Received (in revised form): 6 December 2001
}

\begin{abstract}
This paper reports on ongoing investigations into the use and role of paper mail communications in domestic environments. It utilises ethnographically informed data to analyse how paper mail supports various social roles within the home, particularly a division of labour whereby women tend to be largely responsible for what may be called 'managing the home'. Implications for the future of paper mail are considered and suggestions made about how e-mail tools may be designed to reflect the patterns of social organisation within the home.
\end{abstract}

\section{Background}

In the 1960s, the British government told the Post Office that it would be out of business by the middle of the following decade. Telephones and thereafter fax would undermine the need for written paper-based communications. The Post Office was to prepare for bankruptcy. Forty years later, Consignia, through its brand Royal Mail, delivers more letters than ever before. Why is this? How can assertions about the future of paper mail be so wrong? Why is the business continuing to expand?

These questions have become all the more pertinent at the start of the 21 st century when the impact of the 'digital age' is expected to be greatest. Will paper bills be replaced by electronic bill payment and presentment (EBPP)? Will the much-cherished handwritten letter be replaced by e-mail? And will direct marketing sales literature be delivered to people's Internet addresses rather than to their letter-boxes?

It is no wonder, therefore, that numerous attempts to predict the future of paper mail have been commissioned in the past few years. In Silicon Valley, for example, the Institute of the Future has been funded to look at the future of mail at a global level, ${ }^{1}$ while in Europe various mail companies have funded similar though smaller-scale investigations. ${ }^{2,3}$ The same is happening in Japan. ${ }^{4}$

All of these studies have themes in common. In particular, they include examination of the increasing uptake of the home PC, the widening of access to the Internet and the ever-greater willingness of companies to 


\section{Substitution}

\section{Paperless offices}

\section{The affordances of paper}

offer EBPP. In combination, these factors are said to provide the basis for the substitution of paper mail with digital alternatives.

This existing research has also highlighted certain cultural factors, such as the resistance to home PCs within certain lower-income socio-economic groups in the USA. Here disposable income is utilised in quite different ways from higher-income families, with an emphasis on entertainment (such as with digital TV) and much less on infotainment, as is perceived to be provided with the Web. In Scandinavia there is broader acceptance of computer technologies in the home, and thus it is predicted that substitution will occur more quickly there than anywhere else.

Finally, this research has also uncovered some attitudinal preferences for 'quality paper' in mail, which has suggested that mail recipients view the quality of paper as an indicator of the quality of the sender. Colour and envelope design are obviously factors here as well.

The 'substitution argument', as it is often known, has turned out to be very useful, especially given that it can use basic socio-economic indicators, such as per capita income, to specify the future rates of substitution. Yet there are some doubts about the long-term accuracy of this research since the predictions are not being borne out. As with the predictions that paper mail would disappear by the end of the 1970s, so now there is doubt as to whether these more recent analyses will turn out to be accurate.

\section{A conceptual approach that might provide answers}

This kind of research focusing on the substitution of paper mail by digital technologies brings to mind similar predictions about the future of paper in office environments. At least as early as the mid-1970s, the 'paperless office' was becoming a popular catchphrase, and many pundits prophesied it was merely a matter of time before it became a reality. Investment rates in technology and more user-friendly technology were just a couple of factors that were believed to ensure the eventual paperlessness of offices. But paperless offices never appeared. ${ }^{5}$

The failure of that revolution - and indeed the continuing failure of paperless offices to materialise - was typically explained (and often still is) by reference to what was called 'cultural factors'. According to this view, paper continues to be used because those generations of people who were brought up with paper documents find it difficult to move towards screen-based documents and new technological tools. As this generation gradually retires, so digital documents will replace paper.

As it happens, investigation of this thesis indicates that there is very little relationship between age cohort and preference for paper. Instead, research has suggested that the reason why paper continues to be so important in office life has to do with its 'interactional properties', or those physical aspects of paper which shape the ways in which it can be used in a whole range of different kinds of tasks. ${ }^{6,7}$ These may be thought of as the affordances of paper.

It is worth mentioning what some of these affordances might be since the parallels between these and the affordances of paper mail would seem intuitively obvious. In office environments, paper affords ease of marking. 


\section{cross-referencing}

\section{Oiling organisational wheels}

\section{Interaction with paper}

This turns out to be important when people are trying to review the contents of a document, allowing them to write and comment on the text as they read. One might image that, similarly, recipients of paper mail would utilise the same affordance when, for example, they tick or cross out items on a bank statement when they 'balance the books'.

Studies in offices show that paper also affords flexible crossreferencing between multiple documents, allowing users to spread pages out in physical space and to read and write 'across' documents. This is important when people are trying to compare and contrast between documents or extract and integrate information across documents (all of which are common office activities). Similarly with mail, one can imagine that when someone is balancing the books as just mentioned, such cross-referencing of information may also occur and that therefore this particular affordance of paper would also offer benefits alongside the ability to mark up and annotate. Items delivered through the post that may afford this facility would include not only bank statements, but such things as car insurance certificates that need to be checked against other paper documents, and so on.

It is not so easy to see how other affordances of paper important in offices provide benefits in the home, however. For example, paper also affords complex, two-handed navigation within and between documents. This enables office workers - particularly knowledge workers - to get to grips more effectively with the structure of a document by allowing them to flick quickly through and feel 'where they are'. One cannot readily imagine how people in home settings having a need to satisfy the same requirement. Of course they may do. But this is an empirical question. Similarly, in offices paper affords people opportunities to interact and communicate. Occasionally, for example, they may print-out 'hard copy' so as to justify hand delivery of an important document to their boss, rather than e-mail it. This may allow them to impress their boss, as well do a little bit of 'networking'. These may seem ephemeral needs, but studies of offices show that such practices oil the wheels of organisational process. ${ }^{8}$ It is not easy to see how such affordances may play a role in home settings.

\section{An approach to paper mail}

Irrespective of whether there are complete parallels or not, these studies of office life suggest how one might look at the properties of paper mail with regard to home settings. The research that generated these insights into the role of paper in office life required qualitative and observational research methods, which had hitherto not been utilised by those interested in the role of paper. In particular, a mix of ethnographic investigations, combined with a concern for the 'interactional properties' of artefacts (which happened to be paper but could be any relevant artefact including computational material), lead to insights about the forms of interaction that people in office environments require. ${ }^{9-11}$

It was in light of this research that Consignia funded a research programme at the University of Surrey's Digital World Research Centre (DWRC) which utilised the same qualitative approach to investigate 


\section{Ethnographies of home life}

\section{Hybrid methods}

whether there are similar interactional properties of paper mail (similarly conceived of as affordances) which are and which may continue to result in the use of paper mail in domestic environments. Some of the findings of this project, with a selection of materials gathered in simultaneous DWRC projects into smart homes, are presented here.

\section{The method}

The following programme of activities, to be entitled 'Affordances of Paper Mail', was undertaken. First, the DWRC undertook an ethnographic study of a panel of 11 households: two single households, two young couples, two older couples, a student household and four families with children. The income ranged across the spectrum. Needless to say, though an attempt was made to ensure that a wide range of households were covered, given the total number that it was possible to look at in ethnographic work it was not possible to obtain a truly representative example of all UK households.

The studies were undertaken over two periods, with the first being a pilot investigation and the second a more in-depth examination of what letters people chose to read, how the letters were moved around the home and why, and subsequent communications resulting from the opening of mail. Key to this analysis was a focus on the interactional properties of paper mail, namely its affordances.

Data from this activity formed the basis of two other subordinate strands of research activity. The first of these was a small experiment. The experiment investigated some of the properties of searching and cataloguing envelopes, and this provided further insight into what the affordances of paper mail might be by contrasting those provided by e-mail alternatives. The experiment investigated these questions in relation to the task of receiving and sorting mail, whether it be delivered via paper or digital media.

The second task was a small survey of about 200 persons. The questions used in the survey were put together on the basis of the ethnography and were designed to provide quantitative indicators about the frequency with which letters are used to support various patterns of social behaviour within homes, patterns which relied in one way or another on the affordances of paper mail.

\section{An overview of findings}

In brief, the results of the research show that paper mail does offer specific affordances that add value at the point of use over and above the affordances of other communications media, particularly e-mail tools as currently designed. ${ }^{12}$ Some of these affordances are ones important in office settings; others are quite new. Perhaps of most interest, however, is the fact that some important affordances are those that support how members of households do things together. These may be called 'social affordances'.

For example, it has been well known for some time that certain types of mail are 'broadcast' in the home. Postcards are an obvious example of this. Various attempts have been made to offer similar broadcasting of 


\section{Sharing letters}

\section{Family life}

\section{Public and private}

images in computationally mediated ways, e-cards being the least interesting. More creative ideas can be found. ${ }^{13}$ The HomeNet project is also reporting some of the ways families 'share.$^{14}$ But the present research showed that all types of mail can be shared within households. This was found both in the ethnographic data and in the small-scale survey, which showed that women will share up to 57 per cent of the letters addressed to them (this includes all types of letters, from personal to direct mail), while men share an astonishing 69 per cent, including personal letters. Tables 1 and 2 present details of this.

The interesting issue here is not that mail is broadcast, however, it is why. In summary, the reasons have to do with how letters in paper form are broadcast and moved around the house in a fashion that supports the social organisation of the family. Sharing or broadcasting letters is one element in this social organisation.

An interesting example - and indeed an unexpected use of sharing is the way it is used by parents to monitor and control their children. This

Table 1: Do you ever show letters or other mail to other members of the family or make sure they see them?

\begin{tabular}{|c|c|c|c|c|c|c|}
\hline & \multicolumn{4}{|c|}{ Show letters/other mail? } & \multicolumn{2}{|c|}{ Total } \\
\hline & \multicolumn{2}{|r|}{ Yes } & \multicolumn{2}{|r|}{ No } & \multirow[t]{2}{*}{$\%$} & \multirow[t]{2}{*}{ Number } \\
\hline & $\%$ & Number & $\%$ & Number & & \\
\hline Male & 69 & 55 & 31 & 25 & 100 & 80 \\
\hline Female & 57 & 74 & 43 & 55 & 100 & 129 \\
\hline Married/with partner & 77 & 99 & 23 & 29 & 100 & 128 \\
\hline Widowed/divorced/separated/single & 37 & 30 & 63 & 51 & 100 & 81 \\
\hline Socio-economic groups ABC1 & 67 & 68 & 33 & 33 & 100 & 101 \\
\hline Socio-economic groups C2DE & 56 & 61 & 44 & 47 & 100 & 108 \\
\hline Children under 18 & 76 & 69 & 23 & 21 & 100 & 90 \\
\hline No children & 50 & 60 & 50 & 69 & 100 & 119 \\
\hline All & 62 & 129 & 38 & 80 & 100 & 209 \\
\hline
\end{tabular}

Table 2: What sort of letters or other mail do you tend to share with other members of the family?

\begin{tabular}{|lcrr|} 
& Sample & \multicolumn{2}{c|}{ As \% of } \\
\cline { 2 - 4 } & (number) & Sharers & Total sample \\
\hline Personal/family letters or cards & 113 & 88 & 54 \\
Personal affairs (tax etc) & 52 & 40 & 24 \\
Catalogues & 14 & 11 & 7 \\
Business mail (for work at home) & 8 & 6 & 4 \\
Direct mail & 4 & 3 & 8 \\
Other & 16 & 12 & 62 \\
Total 'sharers' & 129 & 100 & 38 \\
Non-sharers & 80 & & 100 \\
Total & 209 & & 2 \\
\hline
\end{tabular}

These figures are low since the bulk of this material is thrown away as soon as it is received. 


\section{Teaching kids}

\section{Difficult teenagers}

\section{Managing men}

monitoring can take surprising forms. Parents will not only sift out what they believe their children should or should not receive; sometimes they will ensure that their children know that this is being done. In the ethnographic data, one parent wanted to give a direct mail offer of a loan to her son so that 'he would learn to throw it away'. The affordance in question here does not simply consist of an ability to share; this affordance may be thought of as akin to the affordance of paper documents to oil the wheels of organisational life that was previously mentioned. This would seem an unlikely requirement for home settings. But what was found in the empirical studies is that such oiling of the wheels - in this case the wheels of family life — does indeed need to be done. Here it allows such things as parents teaching abilities and skills to offspring. Such didactic practices, sometimes resisted and resented no doubt, constitute a key need (or function) of families.

There is a related affordance that the ethnography also uncovered, and this has to do with how paper mail has to be 'bumped into'. To illustrate: in one household the parents would open the teenager's mobile phone direct debit statement but knew that, unlike more responsible members of the household, the teenager would not notice a statement judiciously placed on the kitchen table. Moreover, the teenager's asocial hours meant that there was little likelihood that the parents would be able to have a 'handing over' moment when they could raise the question of who was going to pay for it. But the paper statement could be placed in front of the teenager's bedroom door - so this is what they did. Now although the teenager could still manage to walk over the statement - after all, it is not that great an obstacle - he could not do so without seeing it. And this meant that he was thereafter accountable for it. Either of the parents could then ask, 'Well, what about that phone bill? Have you got enough money to pay for it?'; 'What did I say about the price of the mobile phone?'; and so forth. In these ways, then, the fact that paper mail could be placed anywhere provided a key tool in the management of parent-teenager relations.

\section{Managing the home}

The monitoring of children is one thing, but using mail to monitor other members of a household often has to be more discreet than this. In another example from the ethnographic corpus, a wife monitored whether her husband had opened a direct mail catalogue that she thought might be of interest to him. Having identified the article as of interest at the doormat, she placed it where he would see it and then waited two days to see if he did anything. After two days he had not done so, so she threw it away. In another family, the fact that after two days a husband had not done anything with a bill placed by his bedside prompted his wife to take up the task for herself. There were several other examples of similar practices of women managing men. Interestingly, such practices were picked up in the ethnographic research but remained less visible in the survey work. It might be that women are less than willing to declare their power in the home when asked to do so in a public place (the survey was undertaken in the street). 


\section{Workflow in the home}

\section{Virtual broadcasting}

\section{Ceremonies of family life}

Irrespective of the problems of discovering these activities, what the examples do show is that the use of paper mail turns out to be more like workflow control than in the earlier examples where mail was used to support family monitoring (where issues of discipline and learning showed themselves). Workflow is a grand term for technologies (typically electronic and interactive but not always) used to manage, coordinate and monitor tasks. The findings show that paper can be one such technology in a household. Putting a bill on the kitchen noticeboard so that it gets noticed and paid may be thought of as workflow management, as is putting a bill inside a handbag so that it is found when one goes to the shops.

It is the corporeality of paper mail that supports these 'workflow affordances'. Placing a bill in a particular place notifies all concerned what stage a set of tasks has reached. By the same token, the ease with which paper can be moved between points in the domestic workflow regime makes it a technology that can be used with minimal effort.

\section{E-mail in the home}

The affordances of paper mail that are relevant here might seem rather mundane. The fact that a letter can be seen to be in one place rather than another hardly seems a discovery worthy of the name; the fact that a letter can be moved easily is hardly a world-shattering finding. But these properties do start to show their value if one compares them with what one can do with electronic alternatives.

Consider this: e-mail messages can be delivered to one person and presented on a single screen anywhere in the home. Now disregarding questions about what a message says, what this research suggests is that as soon as mail is sorted, recipients within households often start broadcasting it - or at least sharing it in one way or another. It is at this point that some of the differences between e-mail and paper mail start to show themselves. Sharing may be supported in a sequential process with e-mail, when, for example, a mother and child take turns with a screen. Alternatively it can be shared concurrently, with various members of the household having their own screens in various places.

Yet either scenario has problems. In one of the examples above it was seen that sometimes it is the physical handing over of a letter that is a key moment in the process of sharing or broadcasting in domestic settings. E-mail tools cannot readily support this: although they can be used to send or forward messages, what they do not do is support the physical and ceremonial handing over so important in face-to-face situations. One can imagine how new versions of e-mail tools might do this. For example, many hand-held devices or PDAs (personal digital assistants) support the use of infra-red signalling and the exchange of data between terminals. Such data could consist of e-mail. Thus one could image a mother summoning a child and beaming, while face to face, the 'offending e-mail'.

An issue here though is not whether this is possible to design - it certainly is, especially with the arrival of Internet-enabled hand-held communications devices. It is rather that currently this process of family monitoring is supported by the fact that the mother gets line of sight of all 


\section{Geography of the home}

\section{Screen collateral}

\section{Fitting home life}

the mail that comes through the door. Thereby she can act as a gatekeeper. If one was to offer e-mail to individual terminals and PDAs, this would no longer happen. And thus the mother would not know when her son's or daughter's direct debit statement has arrived (or indeed any other form of communication). As it happens this is one reason why teenagers are so keen on texting on mobile phones: it is because Mum and Dad cannot see what they are up to.

Texting aside, it has already been remarked that where a letter is in the geography of the home is a marker of what point a job-to-do has reached. E-mail might support this if the screens are located in places that equate to locations within the domestic workflow. Unfortunately there are at least two reasons why this might be difficult to achieve. First, there would need to be screens in a host of places, and this may create economic difficulties on cost alone. But perhaps a more salient difficulty relates to how these locations are rather flexible and differentially graded. Sometimes the fact that a letter is in the living room means it is a job-to-do-today, but at other times it simply allows a recipient to pick up a letter up when they are, say, having a cup of tea. In other words, the same place can be used for more than one task. According to this view, for e-mail to offer an equivalent affordance to paper mail, not only would there need to be many screens throughout the house, but users would have to forward messages to each screen dependent upon a complex of factors, some of which are ambiguous, as the last example shows. In any event, these studies of smart homes have shown that screens tend to be used for entertainment services, rather than for 'boring things'. In other words, bills would have to compete with Top of the Pops for screen collatoral. When bills are in paper form no such competition exists.

There is another issue over and above the allocation of messages to the right screen. This has to do with whether e-mail can allow members of shared households to monitor one another. The physical demonstrability of paper mail results in what one might call 'system state monitoring' being done unobtrusively and easily: a wife can see at a glance that her husband has not done anything with a bill by the bedside, for example. With screens, such monitoring would become more difficult and intrusive: a wife would have to look over a husband's shoulder when he is doing his e-mail, for example, and what then for the delicate balance of power - and more importantly symbolic power — within a marriage?

A key property of paper mail then is that it acts as a successful technology because it fits into the physical organisation of the home easily. E-mail alternatives could deliver mail but would not necessarily provide the embodiment that facilitates the intersecting of space and social roles within the household. Attempts to improve e-mail alternatives through offering numerous screens for viewing would provide some benefits, though this would create new screen collatoral constraints. Whatever their design, it is probable that they would still not replicate all the affordances of paper mail. In any case, there would be some added burden in terms of screen navigation techniques, and in terms of how one user would be able to monitor. Mobile devices would create new problems, in terms of both obviating opportunities for monitoring and 
allowing for the dispersal of e-mail messages that might undermine some of the workflow management tasks necessary in the home.

\section{Changing users}

Although there might be difficulties, there could be ways of forcing e-mail into the home which would not focus solely on the problems of designing technology. Three come to mind.

\section{Triage}

\section{EBPP}

\section{Power of the consumer}

First, recipients could change their mail-related behaviour. Currently, they subject their mail to what one might call a process of triage which involves somewhat casually planning out some things 'to do now' and some 'at a later time', and then, following on from this, using the affordances of paper to support the domestic workflow. Instead, recipients of e-mail could be more instantaneous in their reactions, paying bills as soon as they arrive, for example, and managing the workflow within the home in a rather heavy-handed way: a wife would not simply watch to see if her husband does pay a bill, say, but would pointedly monitor his e-mail in-tray in the ways already mentioned.

As it happens, one can imagine many utility organisations being very pleased if the response of consumers to the arrival of their bills was more prompt than it is now. One study ${ }^{15}$ has suggested this will be the case. Here, a pilot group of customers did indeed make payments more quickly than before when given EBPP. Unfortunately, that they did so is precisely what one would expect if for no other reason than the so-called Hawthorne effect. According to this, subjects will alter their behaviour simply because they are being watched (see also Rubens, ${ }^{16}$ for a more subtle review of the issues related to e-billing). Whether these same subjects will continue to behave in the same way is quite doubtful. Once over the initial interest in the new method of payment, it is unlikely that recipients of mail (ie the consumers) would accept this. Though both e-mail and paper mail could be technologies that help sustain the business and social affairs of the home, paper does so in a way that allows members of the home to remain in charge. With paper, members of households can do things when they want at the speed they want; paper also allows them to monitor this without being intrusive. In contrast, e-mail could force members of households to behave in accordance with the wishes of the letter sender: something that does not fit into what is sometimes called the "natural order of the home'. ${ }^{17-20}$ Given these disadvantages, cost incentives could be provided to encourage these changes in behaviour.

A second scenario involving some change on the part of recipients seems much more likely. Here, the future of e-mail in the home is one where users simply convert e-mail into paper mail. So if bills, statements, mandates, certificates and other communications were to be delivered electronically, recipients would choose to print them because it is in the paper form that they can be moved around, handed over, cross-referenced and left in certain places to ensure that what needs to be done gets done.

If this turned out to be the case, it would have a host of implications for the ways in which some of the things conveyed by mail would be supported in the future. Consider branding. If it were the case that 


\section{Adding to rather than substituting}

\section{Power in the home}

\section{Terms of address}

recipients printed their mail, then differentiating a brand through, say, quality of paper and printed images (such as logos) would be obviated, since all the mail will be printed on the same device.

In any case, a more likely consequence of this scenario is that users would eventually tire of the hassle and cost of printing mail for themselves and would instead return to the practice of waiting for mail to arrive through the door. But they would also want to receive e-mail too. The reason why domestic users would want e-mail as well is paper alternatives is that the arrival of e-mail might help facilitate the delicate management of their domestic responsibilities: if in the past they would plan their response to mail through reference to, say, the colour of a bill — blue for 'put aside' and red for 'do something about it' — with e-mail they might be able to create a third level of reminder. 'Oops! They are sending e-mail now, I had really better pay', one can hear them say. This would be an especial problem for billing organisations since it may well be that users will opt to continue having e-mail versions of the bills as well traditional paper versions, thus the total costs of the sending organisation will increase rather than decrease.

However, a third scenario does come to mind which is perhaps the most radical of all. This would involve users keeping the best element of current paper-based communications alongside what new technologies might offer, though the success of this would depend very heavily on the businesses being more subtle about how they use B2C than would appear to be the case at the moment. For example, one might imagine a scenario where an organisation using paper mail recognises that some types of information or product offering should be sent to the household, rather than to some particular person within a household. One can image what sort of products and information this may consist of - broadly speaking related to the running of the home and maintaining domestic workflow. Businesses would have to be careful when they send such mail, however, particularly when it comes to addressing, since they need to recognise that most probably they are sending correspondence to the wife-girlfriendmother when they send to a household, rather than anyone else in the home - such as the husband. Women may not want their actual status and power made too explicit in communications. As mentioned, homes contain delicate balances of symbolic and actual power; a misaddressed letter may upset these.

At the same time, one can also imagine other communications and product offerings being sent directly to an individual's PDAs and mobile devices. These sorts of products may have nothing to do with the home and all the tasks related to it and more to do with matters related to that person's 'away from home' world. The authors have not explored what these might be here, but what should be clear is that the disjunction between these two worlds is not at all what it might seem and is related to family structure, age, gender and much else beside. Consider the example mentioned above where the use of mobile phones by teenagers outside of the home is a matter of concern for those who run the home within, ie mum and dad. This simple example attests to the complexities of the divide between home and elsewhere. All the more necessary therefore 
that those wanting to leverage new opportunities with current and future technologies take a more research-based approach to defining how they might explore new B2C opportunities, whether it be via paper mail or digital alternatives, including mobile ones.

\section{Qualitative methods}

\section{Smart homes}

\section{Home work}

\section{Conclusions}

Needless to say, this short paper has presented some interesting empirical findings and then perhaps asked more questions than were started with: if one of the appeals of the substitution argument mentioned at the outset is its elegance analytically, then one of the problems with the qualitative methods used - primarily but not exclusively ethnography - is that they do not always allow researchers to come up with easy answers. ${ }^{21}$ But more importantly, this research was done in the UK, and there may be cultural factors shaping the use of mail - and hence the affordances of relevance - that are different in different countries. For example, the number of bills received by households in the UK is small compared with the USA. This may change the behaviour of people when they receive bills, so it could be dangerous to assume that reactions in the UK will automatically track into the USA. However, many of the aspects of the research, such as women managing the home, do seem familiar to Americans.

These concerns notwithstanding, this paper has presented some findings that may make those who use mail in whatever form think about what actually happens when mail is received, as well as offered some insights for those who are in the business of designing new communications media, particularly media that might support what have come to be called 'smart home' technologies. It has pointed towards the problem of how domestic e-mail tools need to support workflow, for example, and how current e-mail tools simply do not get designed with workflow issues in mind, except insofar as they allow a serial distribution of activities. Workplaces might be organised in something like that fashion, but homes surely are not. As is well known, one of the problems of workflow technologies is related to the question of corporeality, or the lack of it. That is to say that when workflow 'objects' are limited to being virtual, then some of the social organisational properties of distributed tasks are rendered opaque to participants in those tasks. This is one of the reasons why digital-only workflow tools nearly always fail (Abbot and Sarin $^{22}$ being the classic explanatory text of this problem). Yet in the home, the need for corporeality — and all the associated affordances which go with it - is as much a ceremonial requirement as it is a prerequisite for members of the family to be able to monitor just whose job is whose. Of course, members of families do not want to burden themselves with a frame of mind that they may adopt at work and which says 'I need to take account of my responsibilities'. One does not go home to take on a new job, after all. But in practice home life is indeed just like work: it is socially organised and people do rely on each other in often complex and subtle ways to share and distribute tasks. But these are the tasks of family life and family living. Home life requires working at, 
too. This paper has sketched out what some of the characteristics of that social organisation of mail-related work in the home might be.

\section{References}

1. See $\langle$ http://www.iftf.org $\rangle$.

2. Nikali, H. (1995) 'Replacement of letter mail by electronic communication to the year 2010', in Crew, M. A. and Kleindorfer, P. R. (eds) Commercialization of Postal and Delivery Services: National and International Perspectives, Kluwer Academic Publishers, Boston, pp. 223-235.

3. Coopers \& Lybrand Consulting (1998) Substitution Trends and the Market Potential for Communication Distribution Services, Canada Post Corporation.

4. Izutsu, I. and Yamaura, I. (1997) 'Effect of telecommunications on letter mail services in Japan', paper presented to the Conference on Postal and Delivery Economics, 11-14 June, Helsingor, Denmark.

5. Sellen, A. J. and Harper, R. H. R. (2001) The Myth of the Paperless Office, MIT Press, Boston.

6. Ibid.

7. Sellen, A. J., and Harper, R. H. R. (1997) 'Paper as an analytic resource for the design of new technologies', paper presented to CHI '97, Atlanta.

8. Harper, R. H. R. (1998) Inside the IMF: An Ethnography of Documents, Technology and Organisational Action, Academic Press, London and San Diego.

9. Ibid.

10. Harper, R. H. R. (2000) 'Getting to grips with information: Using ethnographic case materials to aid the design of document technologies', Information Design Journal, Vol. 9, Nos. 2-3, pp. 195-206.

11. Harper, R. H. R. (2000) 'The organisation in ethnography: A discussion of ethnographic fieldwork programs in CSCW', CSCW: An International Journal, Vol. 9, pp. 239-264.

12. For a copy of the full report, 'The affordances of paper mail: An investigation into the future of paper mail in the digital age', please contact the authors.

13. Liechti, O. and Ichikawa, T. (2000) 'A digital photography framework enabling affective awareness in home communication', Personal Technologies, Vol. 4, Special Issue on Domestic Design, pp. 6-24.

14. Kraut, B., Sherlis, N., Maning, J., Mudkophadhag, T., and Kiesler, S. (1997) 'HomeNet: A field trial of residential use of the Internet', Proceedings of CHI 97, ACM Press, New York, pp. 77-90.

15. Pitney Bowes (2000) D3 Digital Document Delivery, Pitney Bowes, London.

16. Rubens, S. (2000) 'Statement design in the new world of the Internet', paper presented to Xplor Conference on Electronic Billing and Statements: Industry Trends and Practices, London, 8 February.

17. Rouncefield, M., Hughes, J., O’Brien, J. and Rodden. T. (2000) 'Designing for the home', in Harper, R. H. R. (ed.) Personal Technologies : Special Issue on Home Life, Amsterdam, Kluwer, pp. 76-94.

18. O'Brien, J. and Rodden, T. (1997) 'Interactive systems in domestic environments', in Proceedings of DIS '97, ACM Press, Amsterdam, pp. 247-259.

19. O.Brien, J., Rodden, T., Rouncefield, M. and Hughes, J. (1999) 'At home with the technology: An ethnographic study of a set-top-box trial', ACM Transactions in Computer-Human Interaction, Vol. 6, No. 3, pp. 232-308.

20. Hughes, J. A., O’Brien, J., Rodden, T., Rouncefield, M. and Viller, S. (undated) Patterns of Home Life, Department of Sociology, Lancaster University.

21. Bannon, L. (2000) 'Situating workplace studies within the human-computer interaction field', in Luff, P., Hindmarshm J. and Heath, C. (eds) Workplace Studies, Cambridge University Press, Cambridge, pp. 230-241.

22. Abbott, K. and Sarin, S. (1994) 'Experiments with workflow management: Issues for the next generation', in Proceedings of CSCW' '94, ACM Press, New York, pp. 113-120. 


\section{Further reading}

Buckner, K. and Gillham, M. (undated) Using E-mail for Social and Domestic Purposes: Processes, practices, attitudes, Department of Computer Sciences, Napier University, Edinburgh.

Coopers \& Lybrand for the European Commission (1996). Workshop on the Impact of Electronic Mail on Postal Services, European Union, Brussels.

De Rycker, T. (1987) 'Turns at writing: The organisation of correspondence', in Verschueren, J. and Bertucelli-Papi, M. (eds) The Pragmatic Perspective: Selected Papers from the 1985 International Pragmatics Conference, John Benjamins Publishing, Amsterdam.

Frohlick, D., Chilton, K. and Drew, P. (1997) 'Remote homeplace communications: What is it like and how can we support it?', in Thimbleby, H., O'Conal, B. and Thomas, P. (eds) Proceedings of People and Computers 12, BCS, Edinburgh, pp. 38-41.

O'Hara, K., and Sellen, A. J. (1997) 'A comparison of reading on-line and paper documents', in Proceedings of CHI '97, ACM Press, New York, pp. 335-342.

Plum, M. (1997) 'The challenge of electronic competition: Empirical analysis of substitution effects on the demand for letter services', in Crew, M. A. and Kleindorfer, P. R. (eds) Managing Change in the Postal and Delivery Industries, Kluwer Academic Publishers, Boston, pp. 133-161. 